Rosa $M$ aria $M$ arques 1

Áquilas M endes 2
1 Departamento de Economia, Faculdade de Economia e

Administração/PUC-SP. Rua M onte Alegre 984 Ed. Reitor Bandeira de M elo, sala 131, Perdizes 05014-901, São Paulo SP. rosamarques@hipernet. com.br

2 Departamento de Economia da FAAP/SP.

Centro de Estudos e Pesquisas de Administração.

\section{Atenção Básica e Programa de Saúde da Família (PSF): novos rumos para a política de saúde e seu financiamento?}

\author{
Basic Care and Family Health Program (PSF): \\ new ways to health policy and its financing?
}

Abstract This article examines the adopted strategy by federal and state SU S managers which gives priority to the destination of financial resources to the level of Basic Care and to Family $\mathrm{H}$ ealth Program (PSF). It is given special attention to the expansion of federal resources to municipalities, in a way of incentives directed to Basic Care and to PSF. The article also calls the attention to the states level of government allocation resources in this level of health care and in this program by identifying, particularly, the incentives ways from the states of Ceará, M ato Grosso and Rio Grande do Sul. Lastly, it is discussed some problems in Basic Care and PSF financing system in the level of municipalities, due to the instability of its own resources and to the consequences of the systematic way of federal and states incentives in the autonomy of local health system.

Key words Health Basic Care, Family H ealth Program (PSF), PSF Financing System, PAB, Financial incentives
Resumo Este artigo examina a estratégia adotada pel os gestores federal e estadual do SUS, que prioriza a destinação dos recursos financeiros ao nível de Atenção Básica e ao Programa de Saúde da Família (PSF). D estaca-se a expansão dos recursos federais aos municípios, em forma de incentivos, destinados especialmente à A tenção Básica e ao PSF. 0 artigo salienta, também, a alocação de recursos dos estados a esse nível de atenção de saúde e a esse programa, identificando, particularmente, as formas de incentivos dos governos do Ceará, $M$ ato Grosso e Rio Grande do Sul. Por último, são discutidos al guns problemas no financiamento da Atenção Básica e do PSF em nível dos municípios, tanto pela instabilidade de seus recursos próprios, como pelas conseqüências proveni entes da sistemática de incentivos financeiros federais e estaduais à autonomia do sistema de saúde local.

Palavras-chave Atenção Básica de Saúde, Programa de Saúde da Família, Financiamento do PSF, PAB, Incentivos financeiros 


\section{Apresentação}

O período pós-1995 foi marcado pela expansão da Atenção Básica de Saúde. Essa expansão foi incentivada, em primeiro lugar, pelo M inistério da Saúde (Sousa, 2000) e, posteriormente, pelas secretarias estaduais. Ao mesmo tempo em que isso ocorria, houve avanço no processo de municipalização e no estabel ecimento de novas sistemáticas para o financiamento das ações e serviços de saúde, especialmente em nível da Atenção Básica.

Considerando que essa expansão está reorientando a reorganização da lógica assistencial do SUS, este artigo analisa a estratégia dos gestores federal e estadual do SUS. Inserido numa discussão mais ampla sobre o financiamento do setor, discute-se o crescimento dos recursos financeiros destinados à Atenção Básica, através das tran sferências federais e estaduais a municípios, enfatizando-se o crescimento de recursos para o Programa de Saúde da Família (PSF).

Para isso, na primeira parte, dedicada à expansão do gasto com a Atenção Básica, analisase o movimento, realizado pelo governo federal (M inistério da Saúde), de substituição do pagamento direto aos prestadores pela transferência, destinada, em especial, à A tenção Básica. Destaque é dado aos recursos transferidos na forma de incentivos, através do PAB variável, tal como o PSF. Na segunda parte, voltada para a alocação de recursos dos estados ao PSF, são analisados os diferentes tipos de incentivos financeiros repassados pelas secretariais estaduais de saúde a este programa. Essa parte trata, especificamente, da descrição e análise das experiências dos estados do Ceará, M ato Grosso e Rio Grande do Sul com a alocação de recursos estaduais para a Atenção Básica, em geral, e ao PSP, em particular. Finalmente, na terceira parte, são discutidas al gumas tensões presentes no financiamento da Aten ção Básica e do PSF, tendo em vista a dificuldade crescente da fonte municipal de recursos, bem como a definição antecipada de incentivos financeiros - federais e estaduais - "carimbados" a determinados programas, comprometendo a autonomia do sistema de saúde local.

\section{A expansão do gasto com a Atenção Básica}

A partir de 1997, quando teve início a vigência da N OB/96, a participação dos recursos federais no financiamento da saúde pública apresentou mudança qualitativa. De um lado, a União deixou de usar o pagamento direto ao prestador do serviço de saúde como a forma preferencial de alocar recursos, passando a priorizar as transferências a municípios. De outro, focalizou a Atenção Básica como prioridade, de modo que os recursos a ela destinados foram cada vez mais significativos no total das transferências. Há quem afirme que a N OB/96 - em que pese ser um instrumento na operacionalização da descentralização do sistema, ao incrementar as transferências diretas fundo a fundo no campo da Atenção Básica - pode impedir ou obstaculizar a construção de uma política de saúde fundada nas necessidades locais. Isso porque, ao introduzir o mecanismo de transferência para a Atenção Básica (PAB), rompendo com a lógica de repasse global para a saúde de forma integral (NOB/93), criou as condições para o surgimento das políticas de incentivos financeiros que se seguiram posteriormente. N ota-se que, já em 1997, Bueno e M erhy (1997) afirmavam, de forma contundente, quea N OB/96 iria inibir a autonomia do município, induzindo-o a adotar programas não definidos localmente.

Essas alterações na sistemática da participação do governo federal no financiamento da saúde pública ocorreram em parte como resultado da continuidade da implementação do Sistema Ú nico de Saúde (SUS). Como é sabido, o avanço do SUS resultou em maior participação dos municípios no financiamento da saúde e, portanto, na queda relativa dos recursos da U nião, muito embora eles continuem, de longe, a ser a principal fonte de receita. Para se ter uma idéia, no período 1980-1990 o governo federal contribuía com $77,7 \%$ dos recursos gastos em saúde pública e os municípios com 9,5\% ( $M$ arques e M endes, 2001). Em 1994, esses percentuais já haviam se alterado para $60,7 \%$ e $17,2 \%$. Essa tendência, de queda da participação do governo federal e de aumento da esfera local, se manteve, apesar das oscilações, até 0 ano 2000 (Tabela 1). Ao mesmo tempo em que isso ocorria, os recursos da União assumiram a forma de transferência para os municípios. I sso foi resultado direto da crescente implantação do processo de descentralização do SUS, particularmente a partir do histórico documento "M unicipalização das ações e serviços de saúde: a ousadia de cumprir e fazer cumprir a lei" que introduz a NOB/93.

A responsabilização crescente do município pela execução das ações e serviços de saúde não 
Tabela 1

Gasto público com saúde, segundo origem dos recursos1 (1994-1996 e 2000).

$\mathrm{R} \$ 1.000$ de dezembro de 2001

\begin{tabular}{lccccrcrc}
\hline Anos & Federal & $\%$ & Estadual & $\%$ & Municipal & $\%$ & Total & \% do PIB \\
\hline 1994 & 21.479 .064 & 60,7 & 7.829 .686 & 22,1 & 6.092 .337 & 17,2 & 35.401 .087 & 3,3 \\
1995 & 25.471 .627 & 63,8 & 7.494 .234 & 18,8 & 6.959 .279 & 17,4 & 39.925 .139 & 3,4 \\
1996 & 21.784 .719 & 53,7 & 7.512 .195 & 18,5 & 11.252 .934 & 27,8 & 40.549 .847 & 3,2 \\
2000 & 23.515 .529 & 58,2 & 7.048 .275 & 17,5 & 9.821 .367 & 24,3 & 40.384 .901 & 3,2 \\
\hline
\end{tabular}

Fonte: Siafi/Sidor para gasto federal; IBGE/DECN A para gasto estadual e municipal. Siops para dados de 2000

Elaboração: I pea/DISOC. Deflator: IGP-DI.

10 GPS com base na origem dos recursos contabiliza as transferências intergovernamentais e os pagamentos

dos serviços pela rede própria estadual e municipal, registrando-as como dispêndio da instância transferidora.

Para maiores detalhes consultar Piola e Biasoto Jr. (2000).

poderia - seja pela Lei Orgânica da Saúde, seja pelos princípios da unicidade da direção do SUS, através das três esferas de governo, e da partici pação da comunidade inscritos na Constituição Federal de 1988 - ser implementada sem gerar a necessidade de conceder ao gestor local a possibilidade de planejar o uso dos recursos. É isso que explica o movimento no sentido da substituição do pagamento direto pela transferência. Conforme pode ser visto na tabela 2, em 1993, as transferências a municípios representavam apenas $1,7 \%$ da despesa do $M$ inistério da Saúde; em 1998 passaram para 24\%.

De maneira contraditória, exatamente quando a forma transferências se firma como alternativa à remuneração por serviços produzidos pelo M inistério da Saúde, os recursos federais ganharam um "carimbo", classificando sua destinação. Em que pese as intenções da N OB/96, a separação dos recursos para a M édia e Alta Complexidade (M AC) daqueles destinados à Atenção Básica, mediante a criação do Piso da Atenção Básica (PAB) - fixo ou variável -, reforçou o papel definidor da política de saúde pela esfera federal. D essa forma, o aumento de importância das transferências não foi acompanhado pela autonomia dos municípios na determinação da política de saúde. Esses, dependentes dos recursos federais, passaram a ser me ros executores da política estabel ecida no âmbito federal, o que torna a descentralização e a participação da comunidade princípios cada vez mais esmaecidos, esquecidos em nome da "eficiência" do gasto em saúde (Elias, M arques e M endes, 2001).

A tabela 3 ilustra claramente esse movimento. A queda da participação relativa da remuneração por serviços produzidos efetuados pelo
Ministério da Saúde aos prestadores de serviços da saúde, de 71,34\% para 33,41\% entre 1997 e 2001, e o conseqüente aumento das transferências de $28,66 \%$ para $66,59 \%$ refletiram-se na expansão da despesa com M édia e Alta Complexidade e com a Atenção Básica. No período, a primeira despesa aumentou sua participação no total dos recursos federais de $28,66 \%$ para $40,62 \%$. O bserva-se que, nessa categoria de despesa, a prática de "carimbos" manifestou-se através do crescimento do item Outros (campanhas) e, principalmente, em 2001, a Assistência H ospitalar e Ambulatorial (M AC) foi desdobrada em três. Além da Assistência H ospitalar e Ambulatorial (MAC), foram criados itens específicos chamados "Gestão plena do sistema municipal alta complexidade" $(4,45 \%)$ e "Gestão plena do sistema municipal média complexidade" $(25,6 \%)$. Cabe lembrar que essas novas formas de registro deveram-se à lógica impressa pela N OAS/2001. Essa norma atribui destaque à M édia e Alta Complexidade, pois era considerado que esses níveis de atenção à saúde deveriam ser aprimorados para melhor garantir o processo de regionalização dos serviços de saúde.

Vale lembrar que a NOAS e o processo a ela associado, definido como "regionalização da saúde", em que pese promoverem modificações importantes nas relações entre os gestores do SUS - estaduais e municipais - , acentuaram 0 uso dos incentivos financeiros na qualidade de determinantes da política de saúde. Dito de outra maneira, a forma assumida pelo financiamento (limites financeiros para a média e alta complexidade) acaba configurando a política de saúde e reforçando a centralização pelo M inistério da Saúde, o que cria constrangimentos ao exercício da autonomia local. 
Tabela 2

M inistério da Saúde - distribuição dos gastos por categoria econômica (1993-1998)

Em porcentagem

\begin{tabular}{lrrrrrr}
\hline Gastos & $\mathbf{1 9 9 3}$ & $\mathbf{1 9 9 4}$ & $\mathbf{1 9 9 5}$ & $\mathbf{1 9 9 6}$ & $\mathbf{1 9 9 7}$ & $\mathbf{1 9 9 8}$ \\
\hline Pessoal & 17,9 & 21,8 & 16,5 & 16,5 & 13,2 & 12,8 \\
Outras despesas correntes & 64,5 & 59,7 & 54,7 & 55,4 & 52,3 & 42,3 \\
Investimentos & 0,8 & 1,5 & 1,4 & 0,6 & 0,8 & 0,8 \\
Amortização, juros e encargos & 0,5 & 2,8 & 9,0 & 3,4 & 8,5 & 3,2 \\
Inativos epensionistas & 7,3 & 7,4 & 8,8 & 10,3 & 8,3 & 9,9 \\
Transferências estados e DF & 5,4 & 2,4 & 2,6 & 1,3 & 2,1 & 3,3 \\
Transferências municípios & 1,7 & 2,3 & 5,3 & 10,6 & 12,8 & 24,0 \\
Outros & 2,0 & 2,1 & 1,7 & 1,8 & 2,0 & 3,7 \\
Total & 100,0 & 100,0 & 100,0 & 100,0 & 100,0 & 100,0 \\
\hline
\end{tabular}

Fonte: Siafi/Sidor - Piola e Biasoto Jr., (2000).

Além disso, chama atenção o fato de aumentar, a cada ano, o número de itens "carimbados", para os quais se destinam os recursos federais. Para se ter uma idéia, o Datasus registra, para 1997, apenas cinco tipos de despesa; para 1998, catorze; para 1999, 33; para 2000, 43; e, para 2001, o número de itens registrados atinge a cifra de 77. Esse crescimento dos itens de despesa não assume apenas seu aspecto contábil. Trata-se de recursos vinculados a programas específicos, de maneira que, para o município ser merecedor dos recursos, é condição a implementação da política. Para ilustrar mais uma vez o nível de detalhamento e "engessamento" que está ocorrendo com os recursos federais repassados para os municípios, somente no ano de 2001 , foram criados 25 itens como desdobramento das transferências para ações estratégicas. Essas ações compreen dem, entre outras, campanha de oftal mologia, cirurgias de alta freqüência, cirurgias eletivas, câncer de colo uterino, deficiência auditiva escolar, e deformidade crânio-facial. Para esse conjunto de ações estratégicas foram destinados, em 2001, 0,91\% dos recursos federais gastos com ações e serviços de saúde. Embora esse percentual possa ser considerado pequeno, é indicativo do aprofundamento da política de financiamento da saúde assumida pelo governo federal nos últimos anos.

Os recursos federais transferidos para a Atenção Básica aumentaram significativamente em apenas quatro anos: de $15,68 \%$ em 1998, ampliou-se para $25,06 \%$, em 2001. Contudo, como pode ser visto na tabela 4, a ampliação da partici pação da Atenção Básica no total de recursos repassados pelo governo federal foi de apenas 0,46 ponto percentual, em 2001, refle- tindo a priorização que a N OAS/2001 concedeu ao nível da M édia e Alta Complexidade, como explicado anteriormente. Além disso, embora a NOAS/2001 tenha se preocupado em ampliar 0 Piso da Atenção Básica (PAB ampliado), o que resultaria na ampliação clara da participação desse nível de atenção no total dos recursosfederais, nenhum município se habilitou para essa modalidade durante 0 ano de 2001.

Ao longo do período 1998-2001, o PAB variável assume crescente importância no interior da Atenção Básica: passando de 2,38\% para $12,23 \%$ do total de recursos federais. Por outro lado, chama especial atenção o que ocorreu especialmente em 2001. Nesse ano, pela primeira vez, os recursos destinados para o PAB variável igualaram-se aos repassados para o PAB fixo (12,23\% e $12,22 \%$, respectivamente). Isso foi resultado não só do fato de o volume de recursos destinados ao PAB variável ter aumentado $(26,04 \%)$, como decrescido o volume de recursos transferidos para o PAB fixo (8,47\%).

Entre os componentes do PAB variável, os grandes destaques no ano de 2001 foram o Programa da Saúde da Família e Epidemiologia e Controle de D oenças. Os recursos destinados a esses programas aumentaram em $36 \%$ e $80,5 \%$, respectivamente, quando comparados aos recebidos em 2000. Essa expansão de recursos foi acompanhada pela queda do volume de recursos em todos os outros itens que compõem o $P A B$ variável, com exceção do incentivo à saúde bucal.

A presença cada vez mais importante do Programa da Saúde da Família no interior do $P A B$ variável é marcante em todo o período. $\mathrm{Pa}$ ra se ter uma idéia, entre 1998 e 2001, enquan- 
Tabela 3

Recursos federais do SUS - por tipo de despesa (1997-2001)1

Em porcentagem e R $\$ 1.000$ de dezembro de 2001

\begin{tabular}{|c|c|c|c|c|c|}
\hline Tipo de Despesa & 1997 & 1998 & 1999 & 2000 & 2001 \\
\hline Remuneração serviços produzidos & 71,34 & 55,31 & 45,88 & 38,99 & 33,41 \\
\hline Atendimento ambulatorial (MS) & 38,24 & 26,31 & 20,76 & 19,81 & 17,82 \\
\hline Internações hospitalares (M S) & 33,10 & 29,00 & 25,11 & 19,18 & 15,59 \\
\hline Transferências & 28,66 & 44,69 & 54,12 & 61,01 & 66,59 \\
\hline M édia e alta complexidade & 28,66 & 29,01 & 32,77 & 36,41 & 40,62 \\
\hline Assistência hospitalar ambulatorial (M AC) & 22,74 & 26,14 & 30,83 & 32,75 & 13,90 \\
\hline Gestão plena sistema municipal-al ta complexidade & - & - & - & 0,00 & 4,45 \\
\hline Gestão plena sistema municipal média complexidade & - & - & - & 0,00 & 16,83 \\
\hline Fator de recomposição - $25 \%$ & 5,68 & 1,93 & - & - & - \\
\hline Outros & 0,23 & 0,93 & 1,95 & 3,66 & 5,44 \\
\hline Atenção Básica & - & 15,68 & 21,35 & 24,60 & 25,06 \\
\hline PAB Fixo & - & 13,30 & 15,54 & 14,03 & 12,22 \\
\hline PAB Variável & - & 2,38 & 5,52 & 10,20 & 12,23 \\
\hline Outros & - & 0,00 & 0,29 & 0,37 & 0,62 \\
\hline Ações Estratégicas & - & - & 0,00 & - & 0,91 \\
\hline \multirow[t]{2}{*}{ Total } & 100,00 & 100,00 & 100,00 & 100,00 & 100,00 \\
\hline & $11.344 .692,83$ & $12.925 .493,97$ & $14.337 .331,68$ & $14.345 .080,57$ & $5.075 .979,92$ \\
\hline
\end{tabular}

Fonte: Datasus

Elaboração própria. Deflator: IGP-DI.

1 Regime de competência.

Tabela 4

A A tenção Básica e o gasto do M inistério da Saúde (1998-2001) 1

Em porcentagem e R $\$ 1.000$ de dezembro de 2001

\begin{tabular}{|c|c|c|c|c|c|c|c|c|}
\hline \multirow{2}{*}{$\begin{array}{l}\text { Itens da despesa com } \\
\text { a Atenção Básica }\end{array}$} & \multicolumn{2}{|c|}{1998} & \multicolumn{2}{|c|}{1999} & \multicolumn{2}{|c|}{2000} & \multicolumn{2}{|c|}{2001} \\
\hline & Valor & $\%$ & Valor & $\%$ & Valor & $\%$ & Valor & $\%$ \\
\hline Atenção Básica & 2.027 .185 & 15,68 & 3.060 .806 & 21,35 & 3.529 .115 & 24,60 & 3.778 .555 & 25,06 \\
\hline PAB fixo & 1.719 .084 & 13,30 & 2.228 .075 & 15,54 & 2.012 .877 & 14,03 & 1.842 .306 & 12,22 \\
\hline PAB variável & 308.080 & 2,38 & 791.239 & 5,52 & 1.462 .590 & 10,20 & 1.843 .483 & 12,23 \\
\hline $\begin{array}{l}\text { Programa Agentes } \\
\text { Comunitários de Saúde }\end{array}$ & 143.842 & 1,11 & 264.003 & 1,84 & 327.120 & 2,28 & 317.704 & 2,11 \\
\hline $\begin{array}{l}\text { Programa de Saúde } \\
\text { da Família }\end{array}$ & 66.534 & 0,51 & 139.063 & 0,97 & 429.776 & 3,00 & 584.413 & 3,88 \\
\hline Projeto similar ao PSF & 0 & 0,00 & 0 & 0,00 & 0 & 0,00 & 287 & 0,00 \\
\hline Farmácia básica & 0 & 0,00 & 162.734 & 1,14 & 187.852 & 1,31 & 174.074 & 1,15 \\
\hline $\begin{array}{l}\text { Incentivo a ações básicas } \\
\text { vigilância sanitária }\end{array}$ & 36.130 & 0,28 & 48.904 & 0,34 & 44.290 & 0,31 & 42.941 & 0,28 \\
\hline $\begin{array}{l}\text { Incentivo ações combate } \\
\text { a carência nutricional }\end{array}$ & 61.573 & 0,48 & 176.535 & 1,23 & 180.150 & 1,26 & 163.567 & 1,08 \\
\hline $\begin{array}{l}\text { Epidemiologia e controle } \\
\text { de doenças }\end{array}$ & 0 & 0,00 & 0 & 0,00 & 293.403 & 2,05 & 529.450 & 3,51 \\
\hline Incentivo à saúde bucal & 0 & 0,00 & 0 & 0,00 & 0 & 0,00 & 31.047 & 0,21 \\
\hline Outros & 22 & 0,00 & 41.493 & 0,29 & 0 & 0,00 & 92.766 & 0,62 \\
\hline Total de recursos federais & $12.925 .493,97$ & 100,00 & $14.337 .331,68$ & 100,00 & $14.345 .080,57$ & 100,00 & $15.075 .979,92$ & 100,00 \\
\hline
\end{tabular}

Fonte: Datasus.

Elaboração própria. Deflator: IGP-DI.

1 Regime de competência. 
to os recursos destinados para a totalidade da Atenção Básica foram ampliados em $86 \%$, os recursos para este programa aumentaram em $778 \%$.

\section{Alocação de recursos dos estados ao PSF}

$\mathrm{Na}$ esteira do governo federal, também as Secretarias de Estado da Saúde (SES) têm incentivado a implantação do PSF nos últimos anos, uma vez que esse programa se constitui a principal estratégia para o fortalecimento do nível de atenção básica, assumida pelo SU S como sua porta de entrada.

$M$ ais recentemente, dez secretarias estaduais de saúde - M ato Grosso do Sul, São Paulo, Mato Grosso, Amapá, Tocantins, Paraná, Espírito Santo, M inas Gerais, Sergipe e Ceará - proporcionam incentivos financeiros para a implantação do PSF, ainda que utilizando diferentes critérios de repasses. Algumas dessas secretarias alocam recursos somente a municípios mais pobres (rurais; com baixo Índice de Desenvolvimento Humano - IDH ; comunidades assentadas e quilombadas) e outras buscam atrelar os repasses à expansão da cobertura de saúde da população, através da criação de equipes de saúde da família para todos os municípios.

0 quadro 1 apresenta, de forma sintética, os diferentes tipos de incentivos financeiros utilizados pelos governos estaduais para a implantação do PSF.

A necessidade de complementação de recursos para a implantação do PSF constitui o principal motivo para que essas secretarias estaduais de saúde concedam incentivos aos municípios. Observa-se, no quadro 1, que a maioria dos estados prioriza a utilização de incentivo financeiro no lugar de, por exemplo, doação de equipamentos, reforma, ampliação ou construção de unidades, doação de medicamentos e pagamento de recursos humanos. Segundo pesquisa realizada pelo M inistério da Saúde, entre todos os tipos de incentivos estaduais ao PSF, o financeiro corresponde a $48,6 \%$; enquanto "fornecimento de material didático/educativo", $36,0 \%$; "insumos/medicamentos", $27,2 \%$; equipamentos, 20,5\%; e recursos humanos, $17,7 \%$ (Secretaria de Assistência à Saúde/M inistério da Saúde, 1999).

\section{As experiências do Ceará e Mato Grosso com alocação de recursos}

Alguns dos estados destacados no quadro $1_{\text {, }}$ tais como o Ceará e o M ato Grosso, ampliaram a utilização de incentivos para além do PSF, dirigindo-os para a organização dos sistemas municipais e para ações e serviços de média e alta complexidade. N esses estados, os incentivos estaduais ao PSF integram uma proposta mais ampla de "eficiência" na alocação de recursos financeiros aos municípios. Para se ter uma idéia das metodologias utilizadas pelas secretarias estaduais, torna-se importante abordar cada experiência individualmente.

A Secretaria Estadual de Saúde do Ceará adotou um plano de alocação de recursos aos municípios baseado em três eixos: descentralização, regional ização e melhoria da qualidade de vida. Para garantir a descentralização das ações e serviços básicos de saúde, o Estado destina recursos ao pagamento de agentes comunitários de saúde e garante o provento integral do servidor com vínculo empregatício à SES que exercer atividade em unidade de saúde municipalizada. No tocante à regionalização, a política estadual visa implantar o sistema microrregional de saúde através de auxílio financeiro para manutenção e investimento dos hospitais e unidades ambulatoriais de apoio a micro e macrorregiões de saúde.

Quanto à melhoria da qualidade de vida, a alocação de recursos da SES/Ceará procura apoiar os municípios capazes de garantir a execução de ações e de obter resultados sobre o nível de saúde da população. Dessa forma, são transferidos recursos para: custeio e investimento das unidades básicas de saúde da família dos municípios; treinamento de pessoal vinculado à implantação/implementação de ações e serviços estratégicos; aquisição de medicamentos básicos, especiais e excepcionais; e aquisição de equipamentos dos Centros de A poio Psicossocial (CAPS). 0 incentivo financeiro, na forma de custeio e investimento, às unidades básicas de saúde da família correspondeu, em 2002, a 1,6\% do total de recursos do Tesouro Estadual previstos no orçamento da SES/Ceará.

O PSF e o Programa de Agentes Comunitários de Saúde (PACS) são prioridade no Estado do M ato Grosso e, no entender de sua Secretaria Estadual de Saúde, constituem estratégias fundamentais do "melhor modelo de atenção básica em saúde" (Secretaria de Estado de Saúde do M ato Grosso, 2001). Esta secretaria, além 
Quadro 1

Incentivos estaduais ao PSF

\begin{tabular}{|c|c|}
\hline Estados & Tipo de incentivos e critérios utilizados \\
\hline Mato Grosso do Sul & $\begin{array}{l}\text { Área rural } \\
\text { - R } \$ 15 \text { mil por equipe/ano } \\
\text { Área urbana } \\
\text { - } R \$ 12 \text { mil por equipe/ano } \\
\text { Equipes Saúde Bucal } \\
\text { - modalidade I: } R \$ 5,4 \text { mil por equipe } \\
\text { - modalidade II: } R \$ 7,2 \text { mil por equipe } \\
\text { - mais } \$ \$ 3 \text { mil por equipe implantada, para compra de instrumental } \\
\text { e equipamentos odontológicos. Caso a equipe seja desativada no prazo inferior } \\
\text { a um ano, o adicional será descontado futuramente dos recursos do FMS }\end{array}$ \\
\hline São Paulo & $\begin{array}{l}\text { Custeio } \\
\text { - R } \$ 8,5 \text { mil por equipe/mês } \\
\text { - municípios com baixo IDH } \\
\text { - municípios com áreas de assentamento e comunidades quilombadas } \\
\text { Investimento } \\
\text { - na área de comunicação; meio de transporte; construção e reforma de unidades } \\
\text { de saúde da família } \\
\text { - municípios com áreas de assentamento e comunidades quilombadas } \\
\text { Custeio/Recursos Humanos } \\
\text { - pólos de Campinas e Botucatu - capacitação, formação e educação permanente }\end{array}$ \\
\hline
\end{tabular}

Mato Grosso

Amapá

Tocantins

Paraná

Espírito Santo

Minas Gerais

Sergipe

Ceará
Incentivo à contratação de equipes de saúde da família, incluindo valores adicionais de até $100 \%$ sobre o valor repassado, caso os municípios consigam alcançar os níveis de cobertura estabelecidos pela Secretaria Estadual de Saúde. Os municípios do Baixo Araguaia e do nordeste do Estado recebem $\mathrm{R} \$ 24$ mil por ano e os demais municípios, $\mathrm{R} \$ 14$ mil.

Recursos para o aumento da oferta dos serviços básicos de saúde da família dos assentamentos rurais através do Programa de Apoio à Saúde Comunitária de Assentados Rurais (PASCAR).

- R\$1 mil por equipe/mês

- R\$1 mil por enfermeiro/mês

- R $\$ 1,5$ mil por médico/mês

Supervisão, acompanhamento, avaliação e seleção dos agentes comunitários de saúde

Cessão de odontólogos, biomédicos nutricionistas, assistentes sociais, farmacêuticos, bioquímicos e outros profissionais de saúde aos municípios.

Distribuição de kits com material médico (estetoscópio, esfigmomanômetro, otoscópio, etc.)

$\mathrm{R} \$ 2,5$ mil por equipe/mês

- municípios com população até 14 mil habitantes abrangendo, no mínimo, 80\% da cobertura populacional

- municípios na área da Sudene, com população até 25,5 mil habitantes

Recursos distribuídos conforme população efetivamente atendida.

Cessão de médicos, enfermeiros e especialistas que integram a unidade de referência para esclarecimento de diagnóstico.

Cessão de veículos e equipamentos (termo de comodato)

Recursos distribuídos para custeio e investimento das unidades básicas de saúde da família dos municípios.

Fonte: Departamento de Atenção Básica/M S, em levantamento realizado em junho de 2001. As informações dos estados do Ceará e do M ato Grosso foram extraídas da oficina de trabal ho sobre financiamento e alocação eqüitativa de recursos, realizada no Ceará, em junho 2002. 
dos incentivos do M inistério da Saúde, estabelece mecanismos para facilitar a implantação de equipes de saúde da família nas regiões mais carentes do Estado. M ediante portaria, prevêa concessão de incentivo financeiro do Fundo Estadual de Saúde aos Fundos M unicipais de Saúde, para os municípios que alcançarem a cobertura populacional estabelecida pela SES.

A finalidade principal desse incentivo financeiro é estimular, de forma mais rápida, 0 desenvolvimento do PSF e do PACS, em todo 0 território do Estado. Note-se que esse incentivo, implantado em 2001, assim como outros integram a política de descentralização da saúde, implementada pelo Estado do M ato Grosso desde 1995.

Entre os incentivos utilizados pela SES/M ato Grosso, destacam-se: a) sistema de transferência voluntária (convênio) de recursos financeiros do Fundo Estadual de Saúde aos Fundos M unicipais de Saúde, para custeio das ações de atenção básica, assistência ambulatorial e hospitalar, serviços de apoio diagnóstico e terapêutico e de vigilância à saúde; b) recursos destinados à promoção do Programa de $A$ poio ao $\mathrm{De}$ senvolvimento dos Consórcios I ntermunicipais de Saúde (PACIS), contribuindo para a implementação do sistema estadual de referência e contra-referência; c) recursos financeiros para custeio das ações e dos insumos necessários ao desenvolvimento do Programa de Apoio à Organização do Sistema Estadual de U rgência e Emergência; d) recursos para aumento da oferta dos serviços básicos de saúde da família dos assentamentos rurais promovidos pelo Incra e Intermat/MT, através do Programa de Apoio à Saúde Comunitária de Assentados Rurais (Pascar); e, por último, e) recursos aos municípios que garantirem os serviços nas áreas de reabilitação, hemoterapia e centros de aten ção psicossocial. Particularmente com relação ao PSF, a política de incentivo, além de propiciar recursos financeiros para a contratação de equipes de saúde da família, prevê valores adicionais (até $100 \%$ sobre o valor a ser repassado) caso os municípios consigam atingir os níveis de cobertura estabelecidos pela SES/M T. Para os municípios serem contemplados com o novo incentivo financeiro ao PSF/PACS precisam alcançar uma cobertura populacional conforme os seguintes critérios: a) os municípios com população igual ou superior a 30 mil habitantes precisam atender, pelo menos, $50 \%$ da população; b) os municípios com população entre 10 e 30 mil habitantes devem atingir uma cobertura populacional de, pelo menos, $60 \%$; ec) municípios com população inferior a $10 \mathrm{mil} \mathrm{habi-}$ tantes terão de atender pelo menos $70 \%$ de sua população (Secretaria de Estado de Saúde de $M$ ato Grosso, 2001).

A portaria n. 049 SES/GS 2002 estabeleceu que os municípios do Baixo Araguaia e do nordeste do Estado devem receber $\mathrm{R} \$ 24$ mil como incentivo financeiro anual e os demais municípios, R\$14 mil. Para a SES, a diferença nos valores repassados busca minimizar as desigualdades regionais dos municípios.

A SES exige a assinatura de um Termo de Adesão e Compromisso para o município integrar o Programa de A poio à Saúde Familiar e Comunitária. N esse termo, o município fica comprometido a: preencher o Siops, no prazo de 90 dias; cumprir as metas pactuadas dos indicadores de saúde da Atenção Básica; implementar e manter a regularidade do Sistema de Informações da Atenção Básica e garantir a alocação de recursos estabel ecidos pelo programa.

Observa-se que as experiências de alocação de recursos do Ceará e do M ato Grosso visam aumentar a importância da Atenção Básica no conjunto dos níveis de atenção à saúdee do PSF em particular. M erece destaque o fato de esses dois estados transferirem recursos através do instrumento "fundo a fundo" (Fundo Estadual de Saúde ao Fundo M unicipal de Saúde), o que, a princípio, estaria contribuindo para a autonomia dos municípios. Contudo, a forma como esse repasse tem sido implementado por esses estados segue a mesma lógica utilizada pelo governo federal, isto é, a de "premiar" os municípios que desenvolvem os diferentes programas. $N$ esse sentido, 0 instrumento fundo a fundo torna-se apenas um mecanismo contábil, pois a definição de onde alocar os recursos transferidos não é tarefa do município, de maneira que este é apenas um receptor de recursos. Dito de outra forma, nem o Estado do Ceará e nem o do $M$ ato Grosso repassa recursos de forma global para garantir a expansão da Atenção Básica; mesmo os repasses para esse nível de atenção são "carimbados" previamente.

A preocupação em transferir recursos, visando ao conjunto de ações e serviços de saúde, parece encontrar eco apenas no Estado do Rio Grande do Sul. N esse Estado os recursos do Tesouro Estadual são também transferidos fundo a fundo, porém podem ser utilizados, pelos municípios, para despesas de custeio ou investimento, desde que em ações e serviços públicos de saúde. 


\section{Alocação de recursos global: a experiência gaúcha}

Desde 1999, a SES/RS adota uma política de financiamento que busca a resolutividade da atenção básica e de média complexidade como um todo. Para tanto, o governo estadual entende que a distribuição de recursos deve fortalecer o município como esfera de gestão do sistema de saúde. Isso significa fortalecer os sistemas municipais e respeitar as prerrogativas de gestão dessa esfera de governo, principalmente no tocante à utilização dos recursos financeiros repassados. N esta perspectiva, a SES/RS optou por transferir recursos de forma global - fundo a fundo - sem vinculá-los ao desenvolvimento de determinados programas. Dentre os diversos projetos de al ocação de recursos que a SES/RS desenvolve, destacam-se: M unicipalização Solidária, Regionalização Solidária, Assistência Farmacêutica Básica e Cidadania Alimentar. Especificamente para o financiamento e reordenamento da assistência hospitalar no Rio Grande do Sul, a SES criou o Saúde Solidária. A descrição desses projetos segue as "N otas da apresentação" elaborada pela SES/RS, na Oficina de Trabalho sobre Financiamento e Alocação Eqüitativa de Recursos, realizada no Ceará, em junho 2002.

O projeto M unicipalização Solidária objetiva fortalecer as condições para a gestão e a capacidade de oferta de ações e serviços na esfera municipal. Os valores repassados são calculados com base em critérios técnicos, distribuídos para todos os municípios e transferidos trimestral e diretamente aos Fundos M unicipais de Saúde. A distribuição dos recursos ocorre mediante dez diferentes "frações". A Fração Principal, que orienta a maior parte dos recursos transferidos, está baseada em critérios demográficos, epidemiológicos, de capacidade instalada e financeira, abrangendo oito distintos componentes com pesos diferenciados para a fórmula final de cálculo. São eles: população total; população menor de 14 anos e maior de 60 anos; inverso da capacidade instalada; mortalidade infantil, receita própria utilizada na saúde; inverso da arrecadação municipal; e prioridade da área da saúde no orçamento participativo. As demais "frações" e os critérios de distribuição utilizados dizem respeito à: Fração H ospitais Públicos M unicipais (capacidade instalada e necessidade regional); Fração Sazonal (aumento de população no verão eincremento de ações de vigilância à saúde); Fração Populações Itine- rantes (aumento de população por migração); Fração Saúde Bucal (população total e indicador de qualidade assistencial - prevenção e cobertura); Fração Prevenção Câncer de M ama (população feminina na faixa de risco); Fração para M unicípios N ovos (população total); Fração de Promoção DST/Aids (prevalência de Aids); Fração de Saúde do Trabalhador (população maior de 14 anos); e Fração de População Prisional (população prisional em regime fechado).

Para fins de responsabilidade do município pela resolutividade na atenção básica e nos demais níveis de atenção, a SES/RS considera que os recursos transferidos aos municípios não devem receber qualquer "carimbo". Para tanto, sua utilização deve ser definida pelo Plano de Aplicação, elaborado a partir dos instrumentos de gestão como o Plano M unicipal de Saúde, Quadro de M etas e Agenda M unicipal de Saúde. Esses planos devem ser discutidos e aprovados pelos Consel hos M unicipais de Saúde, valorizando as prioridades específicas de cada município. Dessa forma, é permitido utilizar esses recursos para despesas de custeio e investimento, desde que sejam destinados, é claro, a serviços e ações de saúde. A exigência da SES/RS restringese à prestação de contas, devendo esta ser realizada mediante o Relatório de Gestão, apresentado ao Conselho de Saúde e à Câmara M unicipal.

0 projeto Regionalização Solidária visa fortalecer a organização ascendente de sistemas municipais, microrregionais, regionais, macrorregionais e estadual, facilitando o acesso à atenção de qualidade, resolutiva e humanizada. Os recursos distribuídos pela SES/RS são destinados à manutenção de serviços de referência regional: hemocentros, centrais de regulação, centros de referência em saúde do trabalhador, serviços de média complexidade e projetos especiais e inovadores; e à adequação da assistência hospitalar aos usuários do SUS, de acordo com as pactuações locais e o Plano de Regionalização do SUS do Rio Grande do Sul. De maneira geral, a cooperação técnica e financeira da SES é desenvolvida com os municípios considerados pólos de referência para a organização dos sistemas regionais, macrorregionais e estadual de saúde. Os recursos financei ros também são transferidos do Fundo Estadual de Saúde aos Fundos M unicipais de Saúde, segundo os critérios gerais de população total ( $60 \%$ ) e prioridade regional nas Assembléias do Orçamento Participativo Estadual (40\%). De forma específica, quatro são os tipos de transferências utilizados: 
ampliação da média complexidade (critérios capacidade instal ada e população de referência); H emorrede (capacidade instal ada); Centros de Referência de Saúde do Trabal hador (capacidade instalada); e Centrais M acrorregionais de Regulação (capacidade instalada).

Os proj etos Assistência Farmacêutica Básica e Cidadania Alimentar, por sua vez, prevêem o repasse de recursos próprios da SES/RS aos municípios, segundo os critérios de população total e população em risco nutricional, respectivamente.

Para se ter uma idéia do conjunto da política de al ocação de recursos da SES/RS vale a pena mencionar, mesmo que de forma resumida, o projeto Saúde Solidária (Ferla et al.). Este projeto, que vai além da Atenção Básica, concede apoio e qualificação à assistência hospitalar do SUS. O s recursos são distribuídos conforme critérios técnicos e repassados diretamente à instituição para utilização de acordo com suas necessidades. Para garantir a continuidade dos repasses, a SES/RS exige a manifestação dos gestores municipais e regional ea aprovação do relatório mensal de atividades pelo Conselho de Saúde. Do exposto, verifica-se que a experiência gaúcha de alocação de recursos estaduais nos municípios contraria a lógica de financiamento que vem sendo praticada pelo governo federal e pelos estados destacados no quadro 1 , que priorizam o nível de atenção básica de saúde e o PSF no conjunto da Atenção à Saúde. Isto porque os recursos transferidos aos municípios não têm vinculação específica e são destinados ao dispêndio das ações e serviços de saúde de forma geral.

\section{Tensões do financiamento da Atenção Básica e do PSF}

As regras de distribuição dos incentivos, sejam do governo federal e/ou dos governos estaduais, induziram à implantação de centenas de novas equipes municipais, muitas vezes sem a menor possibilidade de serem mantidas sem esses repasses. Para se ter uma idéia desse crescimento, segundo o M inistério da Saúde, o número de equipes de saúde da família aumentou de 328, em 1994, para cerca de 10.788 em 2001. N esse ano, o PSF estava presente em 4.266 municípios, prestando assistência integral a $36 \mathrm{mi}$ Ihões de brasileiros. Contudo, apesar do crescimento dos incentivos financeiros à Atenção Básica, em especial, ao PSF - através do PAB Va- riável e/ou de todos os recursos estaduais repassados -, o município ainda é responsável por $70 \%$ dos recursos despendidos nesse programa.

A partir do final da década de 1990, o município, entre todas as esferas de governo, é aquele mais atingido pela crise das finanças públicas. Os acordos estabel ecidos com o Fundo M onetário Internacional para o controle do déficit público e o conseqüente monitoramento do governo federal sobre as esferas estaduais e municipais determinaram significativa contenção de gastos. No caso dos municípios, isso resultou na diminuição da participação dos municípios no gasto público total com saúde (de $27,8 \%$ para 24,3\%, entre 1996 e 2000) (Ver tabela 1). Não é de estranhar, portanto, que o volume de recursos da fonte municipal, passível de ser destinada ao PSF, vem se tornando mais escasso. Acrescenta-se ao fato o impacto que a vigência da Lei de Responsabilidade Fiscal (LRF) teve no desenvolvimento do PSF. Em várias municipalidades 0 executivo colocou resistências à continuidade do programa, dado que a LRF exige que as contratações das equipes sejam incluídas no limite das despesas com pessoal - $54 \%$ da receita corrente líquida do município. É importante observar que a despesa com pessoal do PSF, a ser incluído no limite da LRF, é alvo de intensa polêmica entre os municípios e os Tribunais de Contas. Contudo, tudo indica que a partir de 2002 essa discussão foi minimizada. Isso porque, ao final de 2001, o M inistério da Saúde realizou um seminário sobre a operacional ização da Emenda Constitucional n. 29 com os técnicos dos Tribunais de Contas do país, e ali os participantes indicaram uma solução, de curto prazo, que garante a realização do PSF, ressaltando que não se faça apenas uma interpretação literal do texto da LRF. Entenderam que a $L R F$, que regulamenta os artigos 153 a 159 da Constituição Federal de 1988, não pode constranger a ef etivação do direito à saúde, incluída no art. 6o como direito social fundamental. U ma alternativa aventada no seminário seria os Tribunais de Contas registrarem o excesso da despesa com pessoal, quando houvesse eventual superação do limite em razão das despesas com PSF, ressalvando que 0 mesmo ocorreu por força do cumprimento do art. 6o. No caso dessa sugestão ser considerada, os participantes do seminário salientaram que é indispensável que as receitas e despesas dos programas sejam discriminadas da maneira mais clara possível, para permitir a identificação dos valores de cada programa. Para essa 
solução ver "A operacionalização da Emenda Constitucional n. 29 - Relatório do Seminário, com subsídios para o estabelecimento de diretrizes voltadas à aplicação e operacionalização da emenda Constitucional n. 29" (M inistério da Saúde, 2002; Lei de Responsabilidade Fiscal, artigo 18, 2000).

Nesta perspectiva, em um país onde os municípios são caracterizados por apresentarem alto nível de desigualdade de renda e de capacidade de geração de receitas próprias, os incentivos federais (principal mente) e os estaduais cumprem (e deverão continuar a cumprir) papel fundamental na busca da eqüidade do gasto do PSF. Sabe-se que muitos municípios utilizam todo o recurso do $P A B$ fixo e do $P A B$ variável para o custeio das ações do PSF. Isto introduz outras dimensões relevantes na discussão sobre o financiamento desse programa, a saber: a rediscussão do valor do per capita/ano do PAB fixo $(R \$ 10,00)$; a alteração dos incentivos federal e estadual, levando em conta, entre outros, aspectos importantes como a despesa com a equipe do programa eo porte populacional dos municípios; e, por último, talvez o mais importante, a retomada do mecanismo de transferência de recursos de forma global do governo federal aos municípios (fundo a fundo) e dos governos estaduais aos municípios. É bom lembrar que o PAB, quando concebido em 1996, foi pensado como $R \$ 12,00$ por habitante/ano; dois anos após, quando implantado, esse valor foi reduzido para o atual $R \$ 10,00$ habitante/ano.

Isso estaria garantindo a flexibilidade necessária para que os problemas de saúde de cada município, muito heterogêneos entre si, fossem levados em conta, permitindo que os recursos não recebessem qualquer "carimbo". A utilização dos recursos seria definida por meio do Plano de Saúde, valendo-se das prioridades de cada localidade, podendo ser aplicados livremente para despesas de custeio ou investimento, na A tenção Básica ou em qualquer nível de atenção à saúde.

É importante lembrar que não se pode confundir a Atenção Básica com as ações e serviços financiados pelo PAB, e sobretudo ao PSF. Devem ser considerados nesse nível de atenção todas as ações e serviços realizados pela vigilância sanitária, pela vigilância epidemiológica e pelo controle de vetores. Também as ações e serviços não hospitalares de controle de doenças devem ser incluídos no campo da atenção básica. 0 tratamento ambulatorial da Aids, por exemplo, é prestado na rede básica.
Há quem considere que a ênfase na Atenção Básica coloca em risco a integralidade da saúde (Costa e M aeda, 2001; Silva Júnior, 1998; M erhy e Franco, 2000). N um país com as dimensões territoriais e com as desigualdades sociais como - Brasil, qualquer medida que configure a priori a ação de atenção à saúde oferecida à população, através da definição antecipada de incentivos "carimbados", pode comprometer o preceito da integral idade. Embora mais fácil para o desenho do sistema, a organização da atenção, mais especificamente da assistência, não resolve o problema do adequado planejamento ascendente da organização do sistema de saúde.

No tocante à indução dos incentivos federais à Atenção Básica, em particular, ao PSF, há que considerar que, na medida que esses incentivos constituem a única maneira dos municípios viabilizarem recursos novos, a política de saúde a eles associada pode não corresponder às necessidades locais. M ais do que isso, como os valores repassados pelo governo federal não cobrem o custo real dos serviços, os municípios acabam financiando, em parte, as políticas federais, mesmo quando estas não constituem sua prioridade, comprometendo ainda mais qual quer ação voltada às necessidades de sua população. Contudo, há que ponderar que inicialmente a indução foi positiva nos municípios onde não havia qualquer desenho de atenção à saúde.

\section{Considerações finais}

Na segunda metade da década de 1990, é significativa a importância estratégica da Atenção Básica e do PSF na política de saúde implementada pelo governo federal. Entre 1998 e 2001, os repasses efetuados a este nível de atenção cresceram $86,39 \%$, passando de $R \$ 2,027$ bilhões de dezembro de 2001 ( $15,68 \%$ do total dos recursos federais do SU S) para R $\$ 3,778$ bilhões de dezembro de 2001 (25,06\%). Essa prioridade foi, inclusive, incorporada à Constituição Federal através da Emenda Constitucional n. 29, em que é definido que a U nião deve aplicar, pelo menos, quinze por cento de seus recursos nos municípios, segundo o critério populacional e em ações e serviços básicos de saúde, segundo a Emenda Constitucional 29, artigo 7요, § 20.

Nesse período, 0 aumento da importância do PAB variável foi decorrente principalmente da expansão dos incentivos financeiros repassados para a implantação dos PSFs locais. A in- 
trodução desses incentivos significou aumento de poder do Ministério da Saúde na determinação da política de saúde, o qual não é isento de contradições. Além disso, a utilização de incentivos no repasse de recursos financeiros ao PSF não foi, a partir da segunda metade da década de 1990, uma exclusividade da instância federal, estando presentes em alguns estados da federação. Na prática, os estados que adotaram esses incentivos seguiram a lógica do governo federal, "premiando" os municípios que desenvolvem o PSF. Somente o Estado do Rio Grande do Sul repassa recursos de forma global sistemática de fundo a fundo - podendo ser utilizados pelos municípios para despesas de custeio ou investimento, desde que em melhoria de sua gestão local de saúde.

Embora conte com recursos federais e estaduais, o PSF é financiado largamente pelos recursos próprios municipais. Contudo, essa fonte de recursos tem se configurado de maneira problemática a partir da segunda metade da década de 1990. Isso porque, de um lado, a crise das finanças dos municípios dificulta o gasto com saúde e, de outro, há as limitações impostas pela Lei de Responsabilidade Fiscal às despesas com pessoal do PSF.

Um conjunto de pontos importantes deve ser levado em consideração numa discussão sobre o financiamento da Atenção Básica, em geral, e do PSF, em particular. O conceito de Atenção Básica tem sido utilizado de forma restrita às ações e serviços financiados pelo $P A B$, excluindo, por exemplo, àquelas ações não hospitalares de controle de doenças. Isso significa não restringir as ações e serviços ao nível de complexidade da atenção à saúde, mas colocá- las no campo amplo da saúde pública, respeitando o princípio da integralidade do SUS.

No tocante à capacidade de indução dos incentivos federais à política de saúde, sendo os incentivos a principal forma dos municípios viabilizarem recursos novos no campo da atenção básica, a política de saúde a eles associada pode não corresponder às necessi dades locais. Além disso, éimportante lembrar que, como os valores transferidos pelo governo federal não cobrem o custo dos serviços do PSF, os municípios acabam financiando em parte as políticas federais, mesmo quando estas não fazem parte das necessidades prioritárias de saúde de sua população.

Por fim, há que considerar a necessidade de incorporação de novos critérios no processo de alocação de recursos do governo federal aos municípios e do governo estadual aos municípios. A ênfase nesta discussão deve ser a de aprofundar a alocação de recursos segundo critérios inspirados no artigo 35 da Lei Orgânica da Saúde (critérios demográficos, epidemiológicos, de capacidade instalada e financeira).

A experiência gaúcha de alocação de recursos do governo do Estado aos municípios pode servir de inspiração. Isso porque, todos os recursos transferidos aos municípios não têm vinculação específica e são destinados ao dispêndio das ações e serviços de saúde em geral, o conhecido - repasse global. No caso das despesas de custeio dos serviços, esse critério facilitaria a aproximação à realidade específica do município. Às despesas de investimento, poderiam ser escolhidos critérios mais estratégicos, tomando por base a necessidade de contribuírem para a mel hor capacidade de gestão com vista à organização do sistema de saúde local. 


\section{Referências bibliográficas}

Brasil 1996. M inistério da Saúde. Portaria n. 2.203 de 1996. Dispõe sobre a N orma O peracional Básica do SUS 01/96. Brasília.

Brasil 2000. Emenda Constitucional n. 29. Altera os artigos 34, 35, 156, 160, 167 e 198 da Constituição Federal e acrescenta artigo ao Ato das Disposições Transitórias. Brasília, 13 de setembro.

Brasil 2001. M inistério da Saúde. Portaria n. 95 de 26 de janeiro de 2001. Dispõe sobre a N OAS - N orma Operacional da Assistência à Saúde. Brasília.

Brasil 2002. M inistério da Saúde. A O peracionalização da Emenda Constitucional n. 29 - Relatório do Seminário, com subsídios para o estabelecimento de diretrizes voltadas à aplicação e operacionalização da emenda Constitucional n. 29. M inistério da Saúde, Subsecretaria de Assuntos Administrativos. Brasília.

Bueno WS \& M erhy EE 1997. Os equívocos da N O B/96: uma proposta em sintonia com os projetos neoliberalizantes? Conferência $\mathrm{N}$ acional de Saúde On-Line. $\mathrm{Na}$ Seqüência da 10a Conferência N acional de Saúde. Tema: N orma O peracional Básica 01/96 (M imeo).

Costa W \& M aeda S 2001. Repensando a rede básica de saúde e o distrito sanitário. Saúde em D ebate 57(25): 15-29.

Elias P, M arques, RM \& M endes, A 2001. 0 financiamento e a política de saúde. Revista USP 51:6-15

Ferla A et al. 2001. Financiamento e regionalização da saúde: a experiência gaúcha, Divulgação em Saúde para Debate. Cebes, n. 24, dezembro:52-71.
M arques RM \& M endes A 2001. 0 financiamento da atenção à saúde no Brasil. Pesquisa \& Debate 12, 1(19):6591.

M erhy EE \& Franco TB 2000. Programa de Saúde da Família: contradições e novos desafios. In AM Z Ianni $\& C$ Bógus (eds.). Anais do Congresso Paulista de Saúde Pública APSP, São Paulo.

M endes A \& M oreira M 2001. Comentários à lei de responsabilidade na gestão fiscal: lei complementar 101, de 4 de maio de 2000. Cepam, São Paulo, 296pp.

Piola S \& Biasoto Jr. 2000. Finanças e dispêndios: financiamento do SUS, gasto público e base tributária. I pea (Mimeo).

Secretaria de Assistência à Saúde 1999. Ministério da Saúde. Avaliação do Programa de Saúde da Família. Relatório, Brasília. Disponível em <http://www. saude.gov.br>.

Secretaria de Estado de Saúde do M ato Grosso 2001. Caderno do gestor municipal de saúde de M ato Grosso. SES, Cuiabá.

Silva Jr. AG 1998. M odel os tecnoassistenciais em saúde: 0 debate no campo da saúde coletiva. Hucitec, São PauIo, 143pp.

Sousa M F 2000. Gestão da Atenção Básica: redefinindo contexto e possibilidades. Divulgação em Saúde para Debate. Cebes, n. 21.

Artigo apresentado em 23/10/2002

Aprovado em 2/12/2002

Versão final apresentada em 16/12/2002 